\title{
CHRONIC VENOUS INSUFFICIENCY (CVI) - A STUDY OF 100 CASES
}

\author{
MM SHAHIN-UL-ISLAM ${ }^{1}$, MD. ZAHIRUL HAQUE ${ }^{2}$, SAKI MD. JAKIUL ALAM ${ }^{3}$, MESBAHUDDIN \\ NOMAN $^{4}$, FM SIDDIQUI $^{5}$
}

\begin{abstract}
:
This study was carried out in the out patient department of Dhaka Medical College Hospital. 100 patients presented with chronic venous insufficiency during the period of January 2005 to June 2005 were studied to find out the various modes of presentation, risk factors and relationship of symptoms with age, sex and Body Mass Index of the patients. It was found that, maximum patients presented with heaviness in the leg (87\%), followed by aching leg pain (75\%), leg swelling (70\%), cramping leg pain (68\%), tiredness (48\%), burning pain (43\%), engorged leg vein (39\%), restless leg at night (21\%), throbbing leg pain (18\%), itching (13\%), various skin changes without active ulceration (7\%) and active leg ulceration only $3 \%$ of cases. Increasing age of the patients, obesity, increasing number of pregnancy, prolonged standing and sitting position at work were found to be positively correlated with CVI. Advanced age is associated with more advanced stage of CVIaccording to clinical CEAP classification. There is almost equal sex distribution among the stages of CVI except in advanced stage, in stage C4, C5 and C6 there is 10 patients out of them 9 are male and only 1 is female. Relationship of symptoms with BMI of the patients were also sort out and found that, in C3 group of CEAP classification out of 61 patients 46 are obese according to BMI, of which 32 are female and 14 are male and only 17 patients have BMI within normal range, but in other group there is no significant difference in incidence between two groups.
\end{abstract}

\section{Introduction:}

Chronic venous insufficiency (CVI) is one of the most prevalent, frequently unrecognized \& underestimated disease world wide. ${ }^{1}$ It is a progressive disease. ${ }^{2} \mathrm{CVI}$ includes all changes resulting from dilatations of the veins of the lower limbs, incompetence of their valves $\&$ resultant venous hypertension. Presentation of CVI varies, ranging from uncomplicated ankle edema to the most severe forms of post- thrombotic syndrome. ${ }^{3}$ In Europe, the prevalence of venous disorders in subjects aged 30 to 70 has been estimated at between $25 \%$ and $50 \%{ }^{4-6}$ Venous leg ulcer is certainly one of the most severe complications of CVI. Its prevalence in the general population is between $0.1 \%$ and $3.2 \% .{ }^{7}$ There is no study on CVI in our country. This study was designed to see various mode of presentation of Chronic Venous Insufficiency, to find out the risk factors and to see relationship of various symptoms of Chronic Venous Insufficiency with age, sex \& body mass index of the patients.

\section{Materials and methods:}

This prospective study was carried out in the OPD (out patient department) of Dhaka Medical College
Hospital. Hundred patients presented with CVI (chronic venous insufficiency) during the period of January 2005 to June 2005 were enrolled in the study. Chronic venous insufficiency was diagnosed on the basis of clinical criteria including leg swelling, heaviness, aching pain, cramp, itching, burning, throbbing, visible veins, skin pigmentations, active or healed ulceration in the leg. Each patient came to medicine out patient department of DMCH with various leg problems mentioned above was carefully interviewed, initially to exclude other cause of leg swelling such as cardiac failure, chronic liver disease, renal failure, nephrotic syndrome, thyroid disease, fileriasis, obvious arthritis in legs \& taking drugs which causes fluid retention such as NSAID's, steroids, calcium channel blockers . After apparent exclusion informed written consent was taken from the patients about the motive of the study. Detailed history was taken and relevant clinical examination was done to all patients. After that, relevant investigations were done to those having suspicion of other cause responsible for edema. Findings of history, clinical examinations and laboratory investigations were recorded in a case record form. Serum albumin and

1. MD Student (Gastroenterology), Thesis Part, Bangabandhu Sheikh Mujib Medical University, Dhaka

2. Clinical Pathologist (Attatched to Medicine Unit White), Dhaka Medical College Hospital, Dhaka

3. Clinical Pathologist (Attatched to Medicine Unit Blue), Dhaka Medical College Hospital, Dhaka

4. Registrar, Department of Nephrology, Dhaka Medical College Hospital, Dhaka

5. Professor of Medicine, Dhaka Medical College Hospital, Dhaka 
urinary albumin was done in all cases and patients having hypoalbuminaemia or proteinuria are finally excluded from the study. A serum albumin $<35 \mathrm{mg} /$ dl was taken as hypoalbuminaemia and urine albumin "+" or more was taken as proteinuria in this study. Serum creatinine, ECG, CXR P/A view, echocardiography, USG of whole abdomen, CFT for fileriasis, serum TSH level were performed in suspected cases and patients having one of the disease may cause leg edema was excluded from the study. Data were coded, edited and entered into computer and were analyzed by using Microsoft Excel program keeping in view the objectives of the study.

\section{Results and Observation}

Among 100 cases of CVI (chronic venous insufficiency) studied, 3 (3\%) were in C0, 11 (11\%) were in C1, 16 (16\%) were in $\mathrm{C} 2,60$ (60\%) were in C3, 5 (5\%) were in $\mathrm{C} 4,2$ (2\%) were in C5 and 3 (3\%) were in C6 according to clinical CEAP classification. (Table-I).

Table-I

Distribution of patients according to clinical CEAP classification

\begin{tabular}{lc}
\hline CEAP & No. of Patients \\
\hline C0 & 3 \\
C1 & 10 \\
C2 & 16 \\
C3 & 61 \\
C4 & 5 \\
C5 & 2 \\
C6 & 3 \\
\hline
\end{tabular}

N.B: C0-no visible or palpable signs of venous disease but patient have symptoms; C1- telangiectasia, reticular veins; C2- varicose veins; C3- edema without skin changes; C4- skin changes; pigmentation, eczema, lipodermatosclerosis; C5- skin change with healed ulceration; C6- skin change with active ulceration

Out of these 100 cases, $52(52 \%)$ were female and 48 (48\%) were male. (Table-II).

Table - II

Distribution of patients according to sex:

\begin{tabular}{lc}
\hline Sex & No. of patients \\
\hline Male & 48 \\
Female & 52 \\
\hline
\end{tabular}

Age of the patient ranging from 24 years to 75 years, maximum patient (57 patients) having age between 31- 50 years, 7 patients are below 30 years, 18 having 51- 60 years, 15 having 61 - 70 years and only 3 patients of this study are more than 70 years of age. (TableIII).

Table - III

Distribution of patients according to age:

\begin{tabular}{lc}
\hline Age (years) & No. of patients \\
\hline$<20$ & 0 \\
$21-30$ & 7 \\
$31-40$ & 25 \\
$41-50$ & 32 \\
$51-60$ & 18 \\
$61-70$ & 15 \\
$>70$ & 3 \\
\hline
\end{tabular}

BMI of all patients were calculated and it shows that 65 (65\%) patients are obese, out of them 42 were female and 23 were male. (Table-IV).

Table - IV

Distribution of patients according to BMI (Body Mass Index):

\begin{tabular}{lc}
\hline BMI $\left(\mathrm{kg} / \mathrm{m}^{2}\right)$ & No. of patients \\
\hline Male & \\
$>25$ & 23 \\
$20-25$ & 23 \\
$<20$ & 2
\end{tabular}

Female

\begin{tabular}{lc} 
BMI $\left(\mathrm{kg} / \mathrm{m}^{2}\right)$ & No. of patients \\
$>24$ & 42 \\
$19-24$ & 9 \\
$<19$ & 1 \\
\hline
\end{tabular}

According to presentation, $87(87 \%)$ patients have heaviness in leg, 75(75\%) patients have aching pain in leg, $70(70 \%)$ have leg swelling, $68(68 \%)$ have cramping leg pain, 48 (48\%) have tiredness, 43 (43\%) have burning pain, 39 (39\%) have engorged leg vein, $21(21 \%)$ have restless leg at night, 18 (18\%) have throbbing leg pain, 13 (13\%) have itching, 7 (7\%) have 
various skin changes including lipodermatosclerosis, eczematization, white atrophy etc and only $3(3 \%)$ patients have active leg ulcer. (Table-V) Maximum patient presented with combination of two or more symptoms, they are shown in Table-VI, Fig.-1.

Table - V

Distribution of patients according to symptomatology:

\begin{tabular}{ll}
\hline Symptoms & $\begin{array}{l}\text { No. of Patients } \\
\text { (Percentage) }\end{array}$ \\
\hline Aching & $75(75 \%)$ \\
Heaviness & $87(87 \%)$ \\
Swelling & $70(70 \%)$ \\
Cramping & $68(68 \%)$ \\
Burning & $43(43 \%)$ \\
Itching & $13(13 \%)$ \\
Tiredness & $48(48 \%)$ \\
Restless leg at night & $21(21 \%)$ \\
Throbbing & $18(18 \%)$ \\
Engorged vein & $39(39 \%)$ \\
Skin changes without ulcer & $7(7 \%)$ \\
Active leg ulcers & $3(3 \%)$ \\
\hline
\end{tabular}

Searching family history, it was found that, only 20 (20\%) patients have positive family history of venous disease, out of them 9 were positive for father, 10 for mother and 1 patient having both father and mother involvement. (Table-VII)

Prolong standing and prolong sitting position in work place is a risk factors for venous insufficiency, in this study it was found that 27 (27\%) patients have history of prolong standing (more than 6 hours in a day) and 35 (35\%) patients have history of prolong sitting ( more than 6 hours in a day) position in work place.

Out of these hundred patients 9 were diabetic, 6 were hypertensive and 1 is with IHD \& HTN.

Table - VIII shows relationship of symptoms with age of the patients. Only positive correlation is patients with $\mathrm{C} 6$ i.e. having active leg ulcers are older age group, all of them are above 60 years of age, other CEAP groups have almost similar age distribution.

Relationships of symptoms with sex of the patients were evaluated and plotted in table-IX. 48 patients are male in this study and according to CEAP classification 2 patients are in $\mathrm{C} 0,3$ are $\mathrm{C} 1,8$ are in $\mathrm{C} 2,26$ are in $\mathrm{C} 3$, 4 are in $\mathrm{C} 4,2$ are in $\mathrm{C} 5$ and 3 patients are in C6 group. In contrast with male, female ( total-52 patients) have no $\mathrm{C} 5$ or $\mathrm{C} 6$ group, more $\mathrm{C} 3$ presentation accounting 35 cases, other groups are almost equal such as 1 in C0, 7 in $\mathrm{C} 1$ and 8 in $\mathrm{C} 2$ group.

Table - VI

Distribution of patients according to reason of consultation:

\begin{tabular}{|c|c|c|c|c|c|}
\hline \multicolumn{2}{|c|}{ With leg swelling (70 cases) } & \multicolumn{4}{|c|}{ Without swelling at present (30 cases) } \\
\hline Symptoms & No. of pt. & \multirow{2}{*}{\multicolumn{2}{|c|}{$\begin{array}{l}\text { With OLS } \\
\text { (9 cases) }\end{array}$}} & \multirow{2}{*}{\multicolumn{2}{|c|}{$\begin{array}{c}\text { Without OLS } \\
\text { (21 cases) }\end{array}$}} \\
\hline Only LS & 11 & & & & \\
\hline $\mathrm{LS}+\mathrm{P}$ & 41 & Symptoms & No of pt. & Symptoms & No of pt. \\
\hline $\mathrm{LS}+\mathrm{P}+\mathrm{EV}$ & 9 & Only OLS & 2 & Only EV & 2 \\
\hline $\mathrm{LS}+\mathrm{P}+\mathrm{EV}+\mathrm{U}$ & 3 & $\mathrm{OLS}+\mathrm{P}$ & 1 & $\mathrm{EV}+\mathrm{P}$ & 18 \\
\hline $\mathrm{LS}+\mathrm{P}+\mathrm{SC}$ & 6 & $\mathrm{OLS}+\mathrm{P}+\mathrm{EV}$ & 6 & $\mathrm{EV}+\mathrm{SC}$ & 1 \\
\hline
\end{tabular}

N.B: LS- Leg swelling; OLS- Occasional leg swelling; P- Pain; EV- Engorged vein; U- Ulcer; SC- Skin changes 
Table-VII

Distribution of patients according to family history of venous disease:

\begin{tabular}{lc}
\hline Positive for & No. of patients \\
\hline Father & 9 \\
Mother & 10 \\
Both & 1 \\
None & 80 \\
\hline
\end{tabular}

Table - VIII

Relationship of symptoms with the age of the patients:

\begin{tabular}{lcc}
\hline CEAP & Age of pt.(years) & Mean age \\
\hline C0 & $32-45$ & 39 \\
C1 & $24-68$ & 45.3 \\
C2 & $35-74$ & 43.43 \\
C3 & $25-75$ & 48.31 \\
C4 & $40-68$ & 56.5 \\
C5 & $52-54$ & 53 \\
C6 & $60-62$ & 61 \\
\hline
\end{tabular}

Table - IX

Relationship of symptoms with sex

\begin{tabular}{lcc}
\hline CEAP & \multicolumn{2}{c}{ No. patients } \\
& Male & Female \\
\hline C0 & 2 & 1 \\
C1 & 3 & 7 \\
C2 & 8 & 8 \\
C3 & 26 & 35 \\
C4 & 4 & 1 \\
C5 & 2 & 0 \\
C6 & 3 & 0 \\
\hline
\end{tabular}

Table X shows relationship of symptoms with BMI of the patients, in C3 group of CEAP classification out of 61 patients 46 are obese according to BMI, of which 32 are female and 14 are male and only 17 patients have BMI within normal range, but in other group there is no significant difference in incidence between two groups.

To find out the risk factors of CVI, age itself is a risk factor, as we have seen that increasing age is associated with advanced stage of CVI. Female sex is not such a risk, as we found sex incidence is almost equal among the 100 patients. Obesity is a major determinant, as we found 65 (65\%) patients were obese in this study. Family history of venous disease also sorts out as a risk factor, but only $20(20 \%)$ patients had positive family history of venous disease. Previous history of venous thrombophlebitis is also important risk factors of venous disease, but in my study only $5(5 \%)$ patients had previous history of thrombophlebitis. Number of pregnancy is also associated with CVI, in this study 45 female out of 52 (86.53\%) patients have 2 or more pregnancy, and this is shown in table-XI. Smoking is also risk factors for venous disease, in these study total 19 patients were smoker, out of them only 1 is female and 18 are male.

Table - X

Relationship of symptoms with BMI

\begin{tabular}{lcccc}
\hline CEAP & \multicolumn{4}{c}{ BMI (KG/M $\left.{ }^{2}\right)$} \\
& $>25$ & $\leq 25$ & $>24$ & $\leq 24$ \\
\hline C0 & 0 & 2 & 1 & 0 \\
C1 & 2 & 1 & 4 & 3 \\
C2 & 2 & 6 & 4 & 4 \\
C3 & 14 & 12 & 32 & 3 \\
C4 & 2 & 2 & 1 & 0 \\
C5 & 1 & 1 & 0 & 0 \\
C6 & 2 & 1 & 0 & 0 \\
\hline
\end{tabular}

Table-XI

Distribution according to number of pregnancy:

\begin{tabular}{lc}
\hline No. of pregnancies & No. of patients \\
\hline Nil & 1 \\
1 & 6 \\
2 & 8 \\
3 & 22 \\
4 & 7 \\
5 & 3 \\
6 & 4 \\
10 & 1 \\
\hline
\end{tabular}




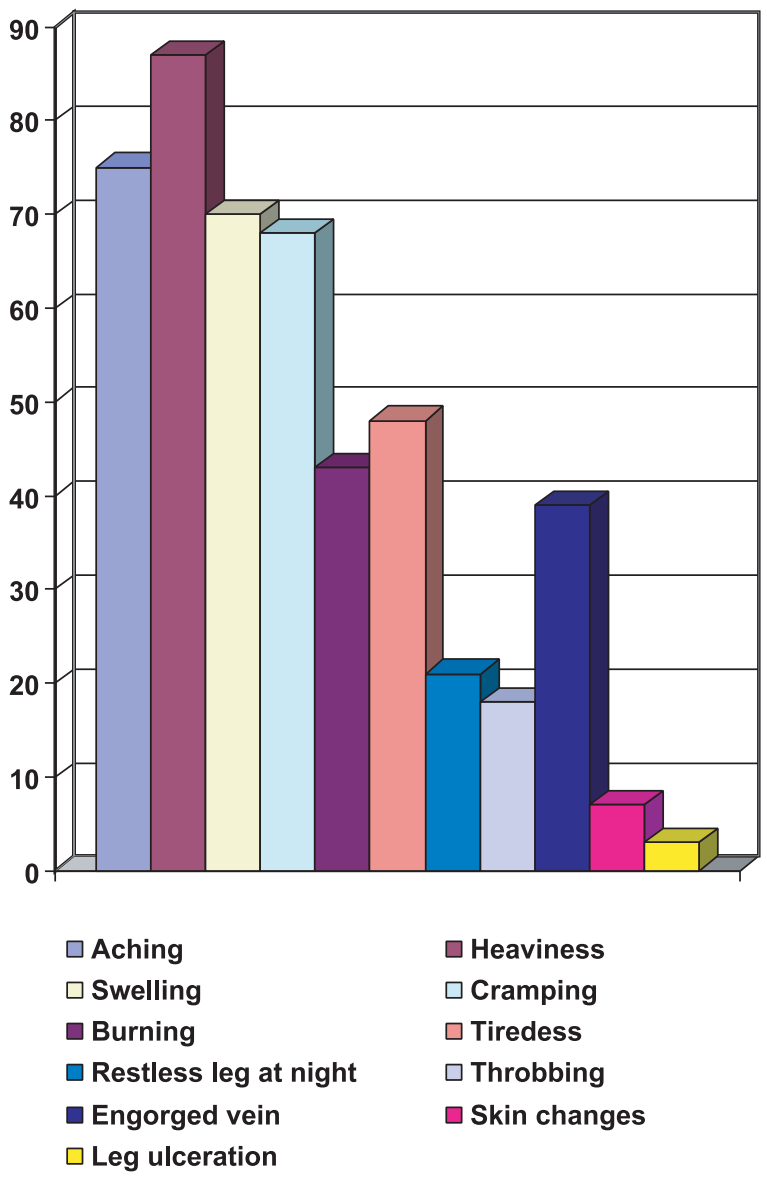

Fig- 1: According to mode of presentation.

\section{Discussion:}

The venous system is one of the largest organs of the body, and venous disease is a burden for the society and a cause of much disability. ${ }^{8}$ Chronic venous insufficiency may affect globally $25-50 \%$ of adult population and its costs both personal to individual and economic to society are well documented. ${ }^{9-17}$ Many contributing factors are involved in the genesis of varicose disease of the lower limbs such as age, sex, heredity, sedentary life style, number of pregnancies, overweight etc. ${ }^{18}$

To find out the relationship between age of the patients and clinical CEAP classification it was found that, higher clinical CEAP classification is associated with increasing age of the patients. Mean age for $\mathrm{C} 0$ is 39 years, $\mathrm{C} 1$ is 45.3 years, $\mathrm{C} 2$ is 43.43 years, $\mathrm{C} 3$ is 48.31 years, $\mathrm{C} 4$ is 56.5 years, C5 is 53 years and $\mathrm{C} 6$ is 61 years. This finding is comparable with RELIEF (Reflux assEssment and quaLity of IIfe improvEment with micronized Flavonoids) study ${ }^{19}$ they shows a higher clinical CEAP classification correlated with increasing age of the patients, mean age of patients in $\mathrm{C} 0$ was 40.3 years and in $\mathrm{C} 4$ it was 54.2 years.

Out of 100 patients 52 were female and 48 were male, this is almost equal in sex distribution, but in the most epidemiological study shows that prevalence of varicose vein is higher in females than in male. ${ }^{20}$ Difference of result may be due to that, in our community females are less aware of health related problem than male, beside this they almost reside in house and does not come out for any kind of job. So, I did not get any significant sex difference in my study.

In the Polish study, ${ }^{21}$ they showed that, advanced form of venous pathology were more frequent in men compared with women. This finding is comparable to my study that, patient having $\mathrm{C} 6$ (the most advanced stage in clinical CEAP) are 3 in number and all are male.

In searching obesity, 63 patients (63\%) out of 100 were obese/ overweight having BMI $>25 \mathrm{~kg} / \mathrm{m}^{2}$ in case of male and $>24 \mathrm{~kg} / \mathrm{m}^{2}$ in case of female. This finding is comparable with the study conducted at the Straub Clinic and Hospital in Hawaii, ${ }^{22}$ they studied 272 patients and found that $61 \%$ of patients were overweight. Out of 63 overweight patients, 42 were female and 21 were male, this is also comparable with analysis of the Balse, ${ }^{23}$ the Framingham, ${ }^{24}$ and the Edinburgh ${ }^{25}$ studies, which shows association between varicose vein and obesity or overweight, is more marked in female than in male.

According to mode of presentation, most patients of this study were presented with clinical C3 groups of CEAP classification, i.e. 61(61\%) patients out of 100 . We know from previous description that C3 means edema of legs without skin changes. But in the community based study of Tecumseh shows $20 \%$ of subjects affected by CVI presents with leg edema. ${ }^{4}$ Number of patients presented with active leg ulceration i.e. C6 were 3 (3\%), this finding is comparable with the study conducted by Cornwall JV, Dore CJ, Lewis JD, they shows $0.1-3.2 \%$ patients presented with leg ulceration. ${ }^{7}$

Prolong standing and sitting position at work has been believed to be associated with the development of varicose vein. ${ }^{26}$ Whereas some studies have pointed to a relationship between long periods of standing and increased incidence of varicose vein, a lack of association had been reported by others. ${ }^{27}$ In the women of the Edinburgh Vein Study, ${ }^{25}$ a clear trend 
of prevalence was seen for the amount of time spent standing. In this study it was found that 27 (27\%) patients have history of prolong standing (more than 6 hours in a day) and 35 (35\%) patients have history of prolong sitting ( more than 6 hours in a day) position in work place.

In this study out of 52 female patients, 45 had 2 or more pregnancy. This finding is consistent with the results from Basle ${ }^{23}$ and Framingham ${ }^{24}$ studies, they shows woman with 2 or more pregnancy have an approximately $20 \%$ - 30\% increased risk of venous insufficiency compared to women with single or no pregnancy.

\section{Conclusion:}

CVI (Chronic Venous Insufficiency) is not so uncommon in our country. Majority of patients presented with the complains of heaviness of leg and unexplained leg swelling, sex predilection is almost same for male and female but advanced stages are more common in male patients. Increasing age is associated with more advanced stage of the disease. There are strong association of CVI with obesity, prolong standing and sitting at working place.

\section{References:}

1. Maffaei HIA, Magaldi C, Piboa SZ, et al. Varicose Vein, and chronic venous insufficiency in Brazil prevalence among 1755 inhabitants of a country town . Int J Epidemiol. 1986; 15: 210 -17.

2. Ramlet A.A. Monti M, Phlebology The Guide. Paris, France, Elsevier. 1999.

3. Ramlet A.A. Monti M, Phlebology The Guide. Paris, France, Elsevier. 1999; 5: 98.

4. Coon WW, Willis PW, Keller JB. Venous thromboembolism and other venous disease in the Tecumseh Community Health Study. Circulation 1973; 4: 839-46

5. Beaglehole R, Prior IAM, Salmond CE, Davidson E, Varicose veins in the south pacific, Int J Epidemiol 1975; 4: 295-99.

6. Abramson Jll. Hopp C, Epstein I.M, The epidemiology of varicose veins, a survey of Western Jerusalem.J Epidemiol Commun Health 1981; 35: 213-17.

7. Cornwall JV, Dore CJ, Lewis JD. Leg ulcers; epidemiology and aetiology. Br J Surg 1986; 73: 69396.

8. Jhon J, Bergan. Update on Fundamental Causes and Management of Chronic Venous Insufficiency.
The Journal of Vascular Disease, Angiology 2003; 54: S1.

9. Sansilvestri-Morel P, Rupin A, Jaisson S, et el: Synthesis of collagen is dysregulated in cultered fibroblasts derived from skin of subjects with varicose veins as it is in venous smooth muscle cells. Circulation 2003; 106: 479-83.

10. Evans CJ, Fawkes FG, Ruckly VC, et el: Prevalence of varicose veins and chronic venous insufficiency in men and women in the general population: Edinburgh Vein Study, J Epidemiol Community Health 1999; 53: 149-53.

11. Nicolaides AN. Investigation of chronic venous insufficiency : a consensus statement. Circulation 2002; 102:e 126-63.

12. Agus GB, Allegra C, Arpaia G, et el: Guideline for the diagnosis and treatment of chronic venous insufficiency. Italian Coll Phlebology, Int Angiol 2001; 20: 1-73.

13. International Task Force: The management of chronic venous disorders of the leg: An evidence based report. Phlebology 1999; 35-42.

14. Valencia IC, Falabella A, Kirsner RS, et el: Chronic venous insufficiency and venous leg ulceration. J Am Acad Dermatol 2001; 44: 401-24.

15. Van den, Oever R, Hepp B, Debbaut B, et el: Socioeconomic impact of chronic venous insufficiency and leg ulcers. An underestimated public health problem. Int Angiol 1998; 17: 161-67.

16. Ruckley CV. Socio-economic impact of chronic venous insufficiency and leg ulcers. Angiology 1997; 48: 6769.

17. De Castro Silva M. Chronic venous insufficiency of the lower limbs and its socio-economic significance. Int Angiol 1991; 10: 152-57.

18. Pistorius Marc-Antoine MD: Chronic Venous Insufficiency: The Genetic Influence 2003; Angiol 54.

19. Jannet G, and the RELIEF Study Group: Chronic venous insufficiency: Worldwide results of the RELIEF study. Angiology 2001; 53: 245-56.

20. Kurz X, Khan SR, Abenhaim L, et el: Chronic venous disorders of the leg: Epidemiology, outcomes, diagnosis and management. Summery of an evidence based report of the VEINES task force. Venous Insufficiency Epidemiologic and Economic Studies. Int Angiol 1999; 18: 83-102.

21. Jawien A, Grzela T, Ochawat A: Prevalence of chronic venous insufficiency (CVI) in men and women 
in Poland: Multicentre cross-sectional study in 40,095 patients. Phlebology, in press.

22. Danielsson G, Eklof B, Grandinentti A, et al: The influence of obesity on chronic venous disease. J Vasc Endovasc Surg 2002; 271-276.

23. Wildmer LK, ed: Peripheral Venous Disorders: Prevalence and Socio-medical Importance, Bern: Hance Huber, 1978; 1-90.

24. Brand FN, Dannenberg AL, Abbott RD, et al: The epidemiology of varicose veins- the Framingham study. Am J Prev Med 1998; 4: 96-101.
25. Evans CJ, Fowkes FGR, Ruckley CV, et al; Prevalence of varicose veins and chronic venous insufficiency in men and women in the general population: Edinburgh Vein Study, J Epidemiol Community Health 1999; 53: 149-53.

26. Jhon J, Bergan. Update on Fundamental Causes and Management of Chronic Venous Insufficiency. The Journal of Vascular Disease, Angiology. 2003: 54: S1;23.

27. Fowkes FGR, Evans CJ, Lee AJ: Prevalence and risk factors of chronic venous insufficiency, Angiology 2001; 52: 5-15. 